\title{
Associations between cognitive impairment, vulnerability and mortality post-stroke: Findings from a five-year follow-up of the ASPIRE-S cohort
}

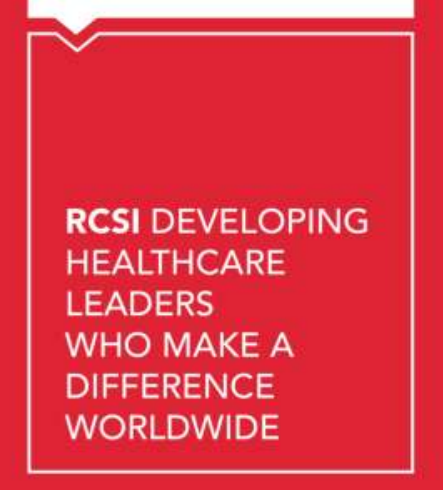

\author{
Eva Gaynor ${ }^{1}$, Daniela Rohde², Margaret Large ${ }^{3}$, Lisa Mellon², Patricia Hall3 ${ }^{3}$ Linda Brewer ${ }^{1}$, Orla Conway², \\ Anne Hickey ${ }^{2}$, Kathleen Bennett ${ }^{2}$, Elizabeth Callaly ${ }^{4}$, Eamon Dolan ${ }^{5}$, David Williams ${ }^{6}$
}

${ }^{1}$ Department of Medicine, Royal College of Surgeons in Ireland, Dublin, Ireland.

2Division of Population Health Sciences, Royal College of Surgeons in Ireland, Dublin, Ireland.

${ }^{3}$ Clinical Research Centre, Royal College of Surgeons in Ireland, Beaumont Hospital, Dublin, Ireland.

${ }^{4}$ Mater Misericordiae University Hospital, Geriatric Medicine, Dublin, Ireland.

${ }^{4}$ Mater Misericordiae University Hospital, Geriatric Medicine, Dublin, Ireland
${ }^{5}$ Connolly Hospital Blanchardstown, Geriatric Medicine, Dublin, Ireland.

${ }^{6}$ Connolly Hospital Blanchardstown, Geriatric Medicine, Dublin, Ireland.
${ }^{6}$ ep

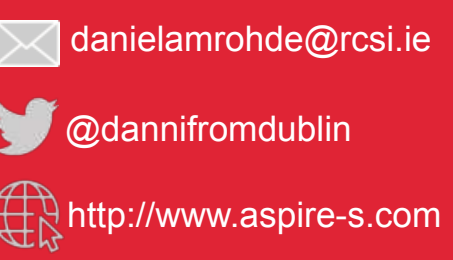

\section{Introduction}

Patients with ischaemic stroke (IS) have a 2-3-fold increased risk of death compared to nonstroke patients. ${ }^{1}$ Numerous cardiovascular risk factors have been associated with increased risks of mortality post-stroke. ${ }^{2}$ Cognitive impairment $(\mathrm{Cl})$, which may be experienced by over half of patients six months post-stroke, is similarly associated with increased mortality risks. ${ }^{3}$ Vulnerability has been found to predict both morbidity and mortality in general older adult populations. No study to date has examined vulnerability and its association with mortality in a dedicated stroke population.

Aim

The aim of this study was to study aims to review predictors of mortality in patients five years post-stroke, focusing on cognitive impairment and vulnerability in addition to cardiovascular risk factors.

\section{Methods}

Study Population and Recruitment

This analysis is based on data from a five-year follow-up of the ASPIRE-S (Action on Secondary Prevention Interventions and Rehabilitation in stroke) cohort. ${ }^{4}$ Full details of the methodology on recruitment and selection have been published previously. ${ }^{5,6}$

Cardiovascular Risk Factors

At 6-months post stroke, eligible patients were followed up. A comprehensive assessment was completed, modelled on the EUROASPIRE protocol for evaluation of the adequacy of secondary prevention in post-discharge cardiac patients. ${ }^{7}$ Clinical measurements including blood pressure measurements, lipid profiles, weight, waist circumference, height, pulse, carbon monoxide levels in smokers were recorded and recent international normalised ratio (INR) readings were reviewed in those on warfarin therapy. Demographic data, background medical history and stroke classification and severity were also recorded.

\section{Cognitive Function}

Cognitive function was assessed at six months post-stroke using the Montreal Cognitive Assessment (MoCA). We applied the recommended cut-off score of $<26$ to identify participants with cognitive impairment.

\section{Vulnerability}

Vulnerability was assessed using the Vulnerable Elders Scale (VES). The VES is a standardised, validated, 13-point self-completion screening tool that identifies vulnerable individuals at risk for health deterioration and death. ${ }^{8}$ The VES assesses limitations in functional abilities, difficulties with activities of daily living, and self-rated health. Scores range from 0 to 10 , with a score $\geq 3$ used to identify vulnerable individuals

\section{Statistical analysis}

Univariate associations with mortality were examined with log rank tests for categorical variables, and univariate Cox regression for continuous variables. Predictors of mortality were examined using multivariate Cox proportional hazards models. Adjusted hazard ratios (HR) and $95 \%$ confidence intervals $(\mathrm{Cl})$ for each model are presented. An alpha level of $p<0.05$ was assumed to denote statistical significance. Data were analysed using Stata ${ }^{\oplus}$ version 13.

\section{Results}

Out of 256 patients last followed up at six months, $63(24.6 \%)$ had died during the follow-up period. In univariate analyses, older age, history of atrial fibrillation, history of stroke/transient ischaemic attack (TIA), vulnerability and cognitive impairment were associated with all-cause mortality within five years.

A number of cox proportional hazards models examined predictors of mortality (Table 2). Both cognitive impairment [HR $(95 \% \mathrm{Cl}): 2.19(1.42,3.39)]$ and vulnerability [HR $(95 \% \mathrm{Cl}): 5.23$ $(2.92,9.36)]$ were significantly associated with mortality at five years. While atrial fibrillation [HR $(95 \% \mathrm{Cl}): 2.27(1.71,3.03)]$ also increased the risk of mortality, a history of stroke/TIA was not associated with mortality in multivariate analyses.
Table 1. Univariate analysis of demographics, stroke event and cardiovascular risk factor profiles, cognitive status and vulnerability by survival status at 5 years.

\begin{tabular}{|c|c|c|c|}
\hline & & $\begin{array}{c}\text { Survived } \\
\text { five years } \\
\text { post-stroke } \\
\text { n (\%) }\end{array}$ & $\begin{array}{c}\text { Deceased } \\
\text { within five } \\
\text { years } \\
\text { n (\%) }\end{array}$ \\
\hline \multirow{5}{*}{ Demographics } & Age (Mean, SD) & $66.2(12.7)$ & $77.7(9.7)^{\star \star \star}$ \\
\hline & Male & $112(58.0)$ & $36(57.1)$ \\
\hline & Married (vs. not married) & $122(63.2)$ & $38(60.3)$ \\
\hline & Living alone (vs. living with others) & $50(25.9)$ & $16(25.4)$ \\
\hline & Private insurance (vs. public) & $59(30.6)$ & $18(28.5)$ \\
\hline \multirow{5}{*}{ Bamford classification } & TACS (Total anterior circulation stroke) & $11(5.7)$ & $4(6.5)$ \\
\hline & PACS (Partial anterior circulation stroke) & $74(38.3)$ & $29(46.0)$ \\
\hline & POCS (Posterior circulation stroke) & $59(30.6)$ & $11(17.5)$ \\
\hline & LACS (Lacunar stroke) & $45(23.3)$ & $17(27.0)$ \\
\hline & Unclassifiable & $4(2.1)$ & $2(3.2)$ \\
\hline \multirow{2}{*}{ TOAST classification } & Cardioembolism & $69(35.8)$ & $31(49.2)^{*}$ \\
\hline & Other & $124(64.2)$ & $32(50.8)$ \\
\hline \multirow{10}{*}{$\begin{array}{l}\text { Uncontrolled vascular risk } \\
\text { factors at six months }\end{array}$} & Hypertension $(n=254)$ & $138(72.3)$ & $42(66.7)$ \\
\hline & TC/HDL-C $(n=221)$ & $38(21.8)$ & $18(38.3)^{*}$ \\
\hline & Impaired fasting glucose $(n=231)$ & $25(14.0)$ & $12(23.1)$ \\
\hline & Overweight/obese $(n=250)$ & $112(59.0)$ & $28(46.7)$ \\
\hline & Smoker & $54(28.0)$ & $17(27.0)$ \\
\hline & History of alcohol abuse & $28(14.5)$ & $9(14.3)$ \\
\hline & History of stroke/TIA & $42(21.8)$ & $22(34.9)^{*}$ \\
\hline & History of heart disease & $53(27.5)$ & $22(34.9)$ \\
\hline & History of carotid stenosis & $31(16.1)$ & $10(15.9)$ \\
\hline & History of AF & $62(32.1)$ & $36\left(57.51^{\star \star \star}\right.$ \\
\hline \multicolumn{2}{|c|}{ Total number of cardiovascular risk factors (M, SD) } & $3(1.3)$ & $3.4(1.6)^{\star}$ \\
\hline Stroke severity $(n=253)$ & Moderate or severe & $38(19.7)$ & $17(28.3)$ \\
\hline Cognitive impairment $(n=226)$ & MoCA $<26$ & $90(50.6)$ & $38(79.2)^{\star \star \star}$ \\
\hline Vulnerability $(n=218)$ & VES $\geq 3$ & $65(37.8)$ & $37(80.4)^{\star * \star}$ \\
\hline
\end{tabular}

Note: ${ }^{*} p<.05,{ }^{* *} p<.01,{ }^{* * *} p<.001$

Table 2. Adjusted Hazard Ratios $(95 \% \mathrm{Cl})$ from Cox proportional hazards models for all-cause mortality based on cognitive impairment, vulnerability, atrial fibrillation, history of stroke/TIA and TC/HDL-C

\begin{tabular}{|c|c|c|c|}
\hline Model & & Adjusted HR (95\% CI)* & $\mathbf{p}$ \\
\hline 1 & Cognitive impairment ${ }^{\S}(n=225)$ & $2.19(1.42,3.39)$ & $<.001$ \\
\hline 2 & Vulnerability $(n=216)$ & $5.23(2.92,9.36)$ & $<.001$ \\
\hline 3 & Atrial fibrillation* $(\mathrm{n}=256)$ & $2.27(1.71,3.07)$ & $<.001$ \\
\hline 4 & History of stroke/TIA $(n=253)$ & $1.26(0.80,1.99)$ & .315 \\
\hline 5 & TC/HDL-C $\$(n=219)$ & $1.90(1.10,3.27)$ & .021 \\
\hline
\end{tabular}

A final model included both cognitive impairment [HR $(95 \% \mathrm{Cl}): 2.16(1.46,3.18)]$ and vulnerability [HR $(95 \% \mathrm{Cl}): 4.87(2.69,8.81)]$, with both predictors independently associated with an increased mortality risk (Table 3 ).

Table 3. Adjusted Hazard Ratios $(95 \% \mathrm{Cl})$ from Cox proportional hazards models for all-cause mortality based on cognitive impairment, vulnerability

\begin{tabular}{lcc|}
\hline Cognitive impairment and vulnerability & Adjusted HR $(95 \% \mathrm{CI})^{*}$ & p \\
\hline Cognitive impairment & $2.16(1.46,3.18)$ & $<.001$ \\
\hline Vulnerability & $4.87(2.69,8.81)$ & $<.001$ \\
\hline
\end{tabular}

$\$$ adjusted for age, sex, and stroke severity. $\mathrm{N}=204$.

\section{Conclusion}

Cognitive impairment and vulnerability are associated with significantly increased risk of five-year mortality post-ischaemic stroke. Identification and management of these risk factors should be emphasised in post-stroke care.

\section{Acknowledgements}

Thank you to all of our participants for taking part in this research. This work was supported by the Health Research Board [SPHeRE 2013/1 and RL-15-1579 (to KB)], and the Irish Heart Foundation (ref.1296829).
References

1. Bronnum-Hansen H, Davidsen M and Thorvaldsen P. Long-term survival and causes of death after stroke. Stroke. 2001; 32: 2131-6. 2. Carter AM, Catto AJ, Mansfield MW, Bamford JM and Grant PJ. Predictive variables for mortality after acute ischemic stroke. Stroke. 2007; 38: 1873-80 3. Oksala NK, Jokinen H, Melkas S, et al. Cognitive impairment predicts poststroke death in long-term follow-up. J Neurol Neurosurg Psychiatry. 2009; 80: 1230-5 4. Rohde D, Williams D, Gaynor E,
BMJ Open. 2017;7(3):e014819.

5. Brewer, L., et al., Secondary prevention after ischaemic stroke: the ASPIRE-S study. BMC Neurology, 2015. 15: p. 216.

6. Mellon, L., et al., Cognitive impairment six months after ischaemic stroke: a profile from the ASPIRE-S study. BMC Neurol, 2015. 15: p. 31.

7. EUROASPIRE. A European Society of Cardiology survey of secondary prevention of coronary heart disease: principal results. EUROASPIRE Study Group.

European Action on Secondary Prevention through Intervention to Reduce Events. Eur Heart J, 1997. 18(10): p. 1569-82.
8. Saliba, D., et al., The Vulnerable Elders Survey: a tool for identifying vulnerable older people in the community. J Am Geriatr Soc, 2001. 49(12): p. 1691-9. 